\title{
Student Crisis Prevention in Schools: The NETWorks Against School Shootings Program (NETWASS) - An Approach Suitable for the Prevention of Violent Extremism?
}

\author{
Nora Fiedler* \\ Freie Universität Berlin, Germany \\ Friederike Sommer and Vincenz Leuschner \\ Berlin School of Economics and Law, Germany \\ Herbert Scheithauer* \\ Freie Universität Berlin, Germany
}

\begin{abstract}
The standardized, indicated school-based prevention program "Networks Against School Shootings" (NETWASS) combines a threat assessment approach with a general model of prevention of emergency situations in schools through early intervention in student psychosocial crises and training teachers to recognize warning signs of targeted school violence. The present review summarized the underlying program theory, gives examples from German cases of severe targeted violence, gives an overview of the program components, and a summary of the evaluation study and its results. Finally, the NETWASS crisis prevention approach is reflected with regard to its feasibility for the prevention of violent extremism.
\end{abstract}

Keywords

Threat assessment, school shootings, NETWASS, crisis prevention, violent extremism

Within the last twenty years student-perpetrated shootings at schools emerged as a worldwide phenomenon. With more than twelve incidents, Germany has experienced more serious attacks targeting

\footnotetext{
*Address for correspondence

Dr. Nora Fiedler and Prof. Dr. Herbert Scheithauer, Department of Education and Psychology, Freie Universität Berlin, Berlin, Germany. E-mail: nora.fiedler@fu-berlin.de (Nora Fiedler) and E-mail: herbert.scheithauer@fu-berlin.de (Herbert Scheithauer)
}

schools than any nation other than the United States (Bondü, Cornell, \& Scheithauer, 2011) resulting in the deaths of 20 teachers and 16 students (Leuschner et al., 2011). Incidents of severe targeted school violence such as school shootings are planned violent acts at a school committed by current or former students with the intention to kill at least one person associated with the school context (Bondü \& Scheithauer, 2014a, b, c; 2015). A key finding from 
school shooting research is that severe targeted school violence is the endpoint of a negative psychosocial development including complex interactions of psychosocial, situational, and structural (e.g. within school environment) risk factors. This negative developmental pathway of a student towards a severe act of violence is associated with observable features, i.e. beside the psychosocial risk factors especially warning and "leaking" behaviors (see below; for an overview of the research literature see Bondü \& Scheithauer, 2014a; Bondü et al., 2011; Leuschner et al., 2017; Scheithauer, Leuschner and NETWASS Research Group, 2015).

This review will describe the theoretical background, preventive framework, and specific features of the NETWASS program, and report selected results from the longitudinal evaluation study. Additionally, structural problems of violence prevention in schools will be highlighted. The NETWASS approach is eventually discussed as a potential strategy to prevent violent incidents associated with radicalization through the early recognition of warning signs and resulting indicated preventive intervention.

\section{The Development of a Psychosocial Crisis and its Escalation}

"From 1994 until 2003/2004, it was also my attempt to have friends, to have fun. When I started at GSS [elementary school] in 1998, everything started with the status symbols, clothing, friends, cell phone and so on. Then I woke up. I realized that my entire life, I was the dumb one for the others, and people made fun of me. And I swore to take revenge! This revenge will be executed so brutally and ruthlessly that your blood will freeze in your veins. Before I go, I will teach you a lesson, so that nobody will ever forget me again! I want you to realize, that nobody has the right to interfere in other's lives under a fascist pretext of law and religion! I want that my face will be burnt into your heads! I don't want to run away anymore! I want to contribute my part to the revolution of the outcasts! I want $R E V E N G E$ !" (Excerpt from a perpetrator's farewell letter; Langman, 2014)

Incidents of severe targeted school violence are not spontaneous, affect-driven acts resulting from the present situation, but instead develop during an extended period of distress, deliberation, and plan- ning (O'Toole, 1999; Verlinden, Hersen, \& Thomas, 2000; Vossekuil, Fein, Reddy, Borum, \& Modzeleski, 2002).The developmental pathway is accomplished by distinct periods of agonizing over violence-related ideas and a targeted planning behavior, often up to several years prior to the shooting (Kidd \& Meyer, 2002; Levin \& Madfis, 2009; Vossekuil et al., 2002). Analyses of international cases suggest that the execution of the violent act is preceded by a psychosocial crisis of the adolescent, facilitated by long-term social strains and acute stressful events, such as the loss of attachment figures or disappointment in future plans (Levin \& Madfis, 2009). In most cases a significant loss of status within the school setting was identified, resulting from bullying, peer or romantic rejection, and unfair teacher behavior (Bondü \& Scheithauer, 2014c; Leary et al., 2003; for a systematic review see Sommer, Leuschner, \& Scheithauer, 2014).

"If you realize you'll never find happiness in your life and the reasons for this pile up day by day, the only option you have is to disappear from this life [...] The only thing I learned intensively at school was that I'm a loser." (Farewell message from perpetrator posted on the internet; Jüttner, 2006).

According to Filipp (1997) a psychosocial crisis can be defined as an event or situation that triggers a threat to identity, loss of orientation, blockade of aims, or re-traumatization resulting from an acute overload of the individual's usual system of coping. Furthermore, research suggests that perpetrators lacked the ability to cope with stressors in a functional manner, or were highly vulnerable, for example, because of emotional disturbances or mental disorders (Langman, 2009; Newman et al., 2004). Narcissistic, as well as depressive tendencies, and in some cases a lack of empathy associated with schizoid symptoms, were found in retrospective case analyses (Bondü \& Scheithauer, 2014b; Hoffmann, Roshdi, \& Robertz, 2009; Kidd \& Meyer, 2002; Langman, 2009; Verlinden et al., 2000; Vossekuil et al., 2002). In the perpetrators' families a weak emotional bonding or parental neglect were found (Bondü \& Scheithauer, 2015; Harding, Fox, \& Mehta, 2002; Wieczorek, 2010). Due to the lack of adequate coping skills, perpetrators then chose inappropriate ways to deal with their crisis and to express their feelings of despair, revenge, and anger. Additionally, cultural scripts such as past school shootings, media violence, and notions of masculinity that glorify armed attack 
provide powerful models for the perpetrators, and serve as prescriptions for behavior.

Furthermore, Böckler and Seeger (2013) suggest the construction of an "imaginary group identity" (e.g. "school shooters", "loners", "fellow-sufferers") based on an imagined community and a shared destiny that provides a sense of belonging and perspective within identity confusion and hopelessness. As findings from violence research show, adolescents turn to (imaginary) violent groups in order to experience feelings of support and experience cohesion to compensate social disintegration and recognition deficits in the school or peer context, or within the family, respectively. Cultural scripts along with (imaginary) membership in a group of "fellowoutcasts", "fellow-sufferers" give new meaning to life and offer a means to regain control and power (Böckler \& Seeger, 2010, 2013; Böttger, 1998; Bondü \& Scheithauer, 2012; Harding et al., 2002; McGee \& DeBernardo, 1999; Newman et al., 2004).

"Eric Harris is God. There is no doubt. It is scary how similar Eric was to me. Sometimes it seems as if I were to live his life again, as if everything would repeat itself. I am not a copy of REB, VoDKa, Steinhäuser, Gill, Kinkel, Weise5 or anybody else! I am the advancement of REB! I learned from his mistakes, the bombs. I learned from his entire life."(Langman, 2014; Excerpt from perpetrator's journal)

None of the risk factors described in the school shooting literature (e.g. peer rejection, lack of parental control, mental abnormalities, easy access to weapons, fantasies of violence and revenge) can be regarded as single causal risk factors nor - in singular or in combination - as sufficient conditions for explaining school shootings, but can usually be found in complex interactions in retrospect. Hence, the perspective on school shootings as one possible, extreme endpoint of a critical, crisis-laden, individual development implies that there is no mono-causal explanation for individual cases of severe targeted school violence but rather that multiple developmental pathways towards severe targeted school violence are observable. Consequently, there is no consistent perpetrator profile to rely on when designing measures for prevention. Scheithauer et al. (2015) integrated results from several studies and analyses of German school shooting cases into a dynamic developmental model, which asserted that the crisis itself could be compounded by stressful events that are closely linked to the motives for the later commit- ted violent act, such as rejection by peers, or conflicts with teachers associated with observable features, i.e. beside the psychosocial risk factors especially warning and "leaking" (or leakage) behaviors.

\section{Leakage, Warning Behaviors, and General Crisis Symptoms as Indicators of a Negative Psychosocial Development}

A psychosocial crisis was consistently associated with certain observable warning behaviors that indicate the planning of a violent act, or the preoccupation with violence, respectively, as well as early crisis symptoms pointing to a negative psychosocial development - as several analyses of school shooting cases suggest (Meloy, Hoffmann, Guldimann, \& James, 2012; Meloy \& O'Toole, 2011). Symptoms for a general crisis that were found in case analyses were school failure, rejection of schooling, social withdrawal, aggressive behaviors, self-injury, psychosomatic pain, or other sudden behavior changes (for an overview see Scheithauer et al., 2015; Leuschner, Schroer-Hippel, Bondü, \& Scheithauer, 2013). Violence-specific warning behaviors are verbal or written threats, leakage of violent intentions, preoccupation with violence, or suicidal intentions (Meloy et al., 2012; Meloy \& O'Toole, 2011). Perpetrators also were fascinated by previous mass shootings, and often identified with the perpetrators (Böckler \& Seeger, 2013). They often had a strong interest in weapons, collected weapons, or had shooting expertise.

"At some point his taste in music changed. He listened to Heavy Metal and very loud music. He also changed his clothing style. I did not like that. He was extremely interested in knives. He also watched many movies, horror movies and thought a lot about the German army. He refused from being with others. (... ) Maybe he felt like a lone fighter. In Internet he bought an ice-hockey mask and a Michael Meyers coat. That is a figure from a horror movie. This figure kills a lot of people, he slaughters them. He watched all movies from the Halloween series, he knew them by heart. (...) In his room all posters were pulled off and he dismantled his bed. Instead he used a soldier's plank bed. His walls were painted with Edding. All walls were black. He wanted everything black. One door of his closet was damaged. He must repeatedly have stabbed with a knife in 
the door. (...) All this resulted in the fact, that I couldn't share his interest anymore. I cut of contact." (Statement from an offender's former friend after the attack; TARGET Project, Original data, modified and analogous translated from German by Target Research Group)

Particularly, the phenomenon of "leakage", defined as communicating an intent to harm a target to a third party (Meloy \& O'Toole, 2011, p. 514) has been observed repeatedly prior to every German school shooting analyzed to date (Bondü \& Scheithauer, 2014a, b, c; 2015), and in most international cases (O'Toole, 1999; Vossekuil et al., 2002), and seems to be a promising approach for prevention efforts. Students communicated their violent thoughts and plans through various channels to peers, sometimes to an adult, or strangers by leaving comments online, writing essays, letters, Internet postings, or other forms of behavioral self-expression (e.g. gestures).

"This fear is slowly turning to rage. I am consuming all this rage and will let it all out at some point to take revenge on all the arseholes who wrecked my life! For those who haven't understood it exactly: Yes, this is about a shooting." (Jüttner, 2006; Message from the later perpetrator in a (non-supervised) internet support forum, June 2004)

Little is known about the motives for "leaking" one's plan or violent fantasies. Different assumptions can be found in the literature: First, a student in trouble probably seeks to express despair and the need for help, or he may test others if they hear and understand a warning, and react adequately by offering support. Second, increasing warning behavior could also indicate that a student more and more identifies with becoming a perpetrator and regards himself as belonging to a group of "revengers" from past school shootings. Third, externalizing violent thoughts from one's fantasy into reality through making a threat or violent statement could also be understood as a "trial" of a violent act (Robertz, 2004).

"It's three weeks ago that he mentioned casually such a school shooting would be cool when we chatted about school shootings in general. But, he never said this in a serious tone. To me, it sounded like a joke so didn't care about this a lot. "(Peer about behavioral changes he noticed in the perpetrator; TARGET Project, Original data, modified and analogous translated from German by Target Research Group)
Thus, leakage can be considered an indicator of a psychosocial crisis or negative psychosocial development associated with violent fantasies and intentions. Simultaneously, the analysis of student threats suggests that leakage can also be observed in students who do not carry out a violent act, however, in terms of early and indicated crisis prevention, leakage provides a promising approach: The early detection and adequate assessment (e.g. by school staff) of leakage allows for the identification of students in need for attention and support (Leuschner et al., 2011).

\section{Schools as Targets and Settings for Prevention - Implications from Research on Structural Risk Factors}

Research provides evidence that a school's organizational complexity and lack of resources are barriers to successful communication and crisis management. Organizational deviance was found in all victimized schools to a certain extent, and is discussed as a significant institutional risk factor for severe targeted school violence, as it puts a school at risk for what is described as "institutional memory loss" in the literature (Fein et al., 2002; Fox \& Harding, 2005; Vossekuil et al., 2002).

A single school staff member's autonomy in dayto-day decision-making, as well as task-segregation result in "structural secrecy" and "loose coupling" on an organizational level (Fox \& Harding, 2005). Typical conflict situations in a school require immediate educational responses, which primarily rely on gut feelings, instead of systematic collegial intervision and an informed rational decision-making procedure. The Berlin Leaking Project indicated a significant lack of knowledge and uncertainty in risk assessment among German school staff (Bondü et al., 2011). Teachers reported a strong need for general sensitization and intense expert training to build awareness for the topic. Participants also demanded for increased support and counseling from their local professional network (Leuschner et al., 2011).

Due to a lack of time, information on student warning behavior is often not shared with colleagues, or reported to authorities, respectively. Instead, an observation of a student behavior of concern remains fragmented within a school and between schools. "Information fragmentation" can also occur when observations of a student behavior are not exchanged with professionals from a school's external network 
and local service institutions. In the long term, a lack of inter-institutional cooperation can become a significant barrier to effective case management and the initialization of supportive measures for an adolescent in crisis (Harding et al., 2002).

Insufficient documentation of observations made is another structural risk factor: Data on apparently harmless disciplinary incidents is often not recorded in a student's file due to law restrictions or a well-meant 'clean-slate' mentality. Information on a student's social biography, familiar background, or psychological particularities literally diffuses and cannot be integrated in case assessment after a student transition to secondary school or another school district. From a developmental perspective, this can have a harmful impact, since teachers at a new school will have difficulty to properly evaluate the progression of a student's crisis.

Finally, retrospective case analyses suggest that in the majority of cases warning behavior prior to the attack was exclusively reported from the later perpetrator to peers. "Code of silence", followed by adolescents to protect peers from trouble with adults, in these cases legitimated a bystander's decision to keep "conspicuous behavior" as a secret. In most of the cases analyzed to date, this behavioral code apparently reduced a peer's willingness to communicate student threats to an adult, and eventually contributed to information fragmentation (Daniels, Bradley, \& Hayes, 2007; Fein et al., 2002; Syvertsen, Flanagan, \& Stout, 2009; Vossekuil et al., 2002).

To the same extent - as schools are high risktargets for student attacks - schools simultaneously are a key environment where children and adolescents spend most of their time and possibly exhibit warning behavior or general crisis symptoms. Provided that signs for a negative developmental pathway are recognized at an early stage of development by school staff, or with the support of parents and peers, schools form an adequate setting for an early and indicated, institution-based crisis prevention. For proper recognition and case management of students at risk schools are in need of preventive approaches that integrate 1) sensitization of the individual teacher in order to recognize warning behavior and risk factors; 2) implementation of organizational structures for effective information transfer on the school level; 3) promotion of an empirically-informed threat assessment and case management procedure based on a structured case management protocol; and, finally, 4) development of a reliable professional network providing expert counseling and case mon- itoring after interventions have been initialized by the school.

\section{Strategies for the Prevention of Severe Targeted Violence in Schools}

In response to tragic cases of severe targeted school violence in schools between 1999 and 2009, all German Federal States implemented emergency response plans as a guideline for crisis management in the case of a violent incident. At the same time, alarm systems were installed as technical features in some schools to improve communication inside the schools, and with law enforcement. However, emergency response should not be the only measure to prevent violent incidents in schools. As opposed to perpetrator profiling and developing checklists of risk factors, a structured threat assessment approach emerged to be a promising intervention strategy according to the literature. In a systematic review (Apelt, 2013) of threat assessment approaches suitable for schools we identified three structured U.S. systems: The Virginia Student Threat Assessment Guidelines (Cornell \& Sheras, 2006), the Mid-Valley Student Threat-Assessment System (Van Dreal, 2011), and the Dallas Threat of Violence Risk Assessment (Ryan-Arredondo et al., 2001).

Research has shown that programs are most effective provided that a strong fit between program and school, i.e. school system, respectively, is guaranteed (Payne, Gottfredson, \& Gottfredson, 2006). Adopting the U.S. approach to threat assessment (e.g. Cornell, Allen, \& Fan, 2012; Cornell \& Sheras, 2006) would not have adequately taken into account for country-specific legal restrictions, emergency guidelines, and community services, as well as differential offense patterns (e.g. German cases revealed a higher casualty rate for teachers than for students (Bondü \& Scheithauer, 2015; Sommer et al., 2014). As opposed to most US schools, German schools lack a multidisciplinary student support staff (i.e. school psychologists, school resource officers), and a multidisciplinary threat assessment is not feasible. School psychologists in Germany for instance are not associated with a specific school, but offer service for larger districts, and are rarely present on site.

Additionally, schools usually maintain cooperation with local professional partners limited to the duration of certain projects, but those are currently not involved in case management routines necessary for crisis prevention. For those reasons, a main focus in 


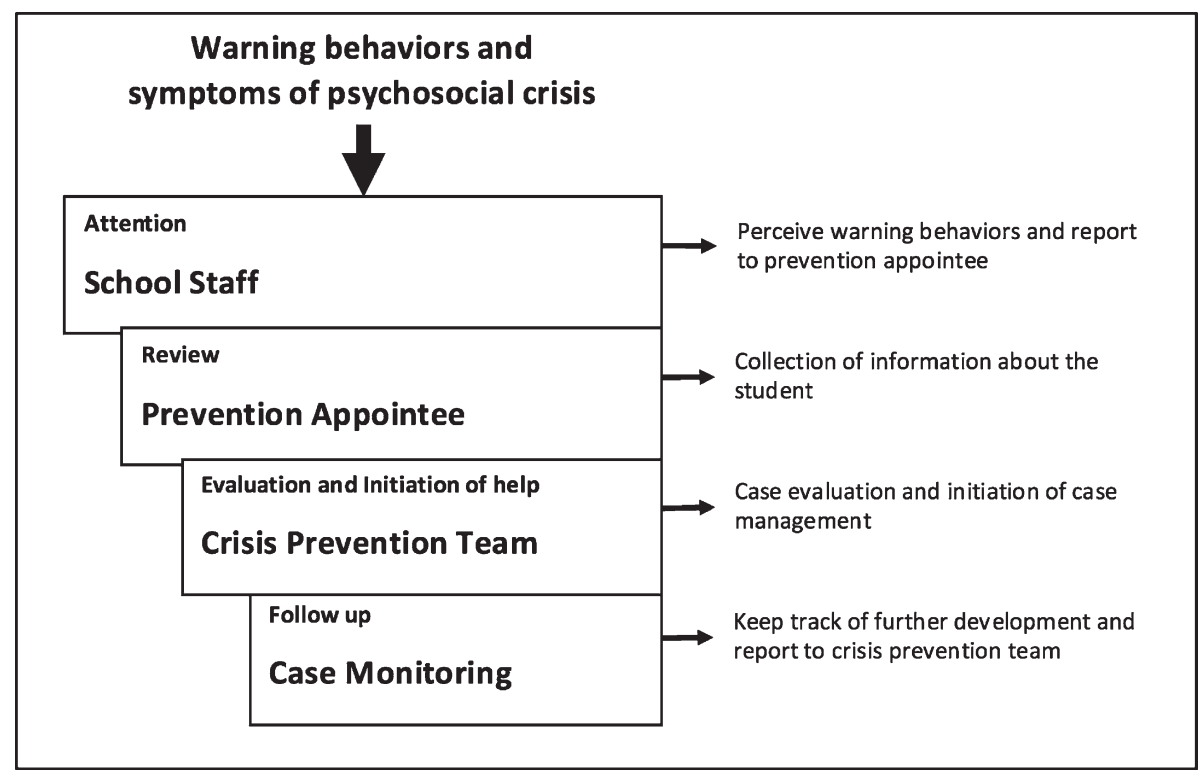

Figure 1. The NETWASS crisis prevention model for schools (from Leuschner et al., 2013, p. 408; transl. by authors).

Germany must be on teacher trainings to build threat assessment and case management skills, and increase knowledge on the topic, as well as on promoting sustainable networking with external partners, rather than on school-based multidisciplinary teams like in the US.

\section{The NETWASS Model of Early and Indicated Prevention: Four Steps Towards Effective Crisis Management}

Based on the research results and practical concerns described above, between 2009 and 2013, a research team at Freie Universität Berlin (Germany) developed the NETWorks Against School Shootings (NETWASS) program (Scheithauer et al., 2015) as an intervention framework for schools. The NETWASS approach is based on a developmental perspective on school shootings grounded in contemporary empirical research. It combines the advantages of a threat assessment approach with a more general model of prevention of emergency situations in schools (e.g. severe targeted school violence) through early interventions with students experiencing a psychosocial crisis, and includes recommendations for building an organizational structure for school-based crisis prevention. The overall goal of the program is to provide school staff with knowledge and skills to recognize a student experiencing a psychosocial crisis that could lead to violence, and enable them to reliably assess a warning behavior, and to implement supportive measures in order to provide help to students in trouble.

As illustrated in Figure 1, the preventive model consists of four process steps and works like a filter in which information is collected and reviewed with only the most serious cases passed on for consideration by a crisis prevention team (Leuschner et al., 2013):

(1) In a standardized face-to-face training, all school staff is sensitized to increase awareness for students in trouble/crisis. If a warning or other conspicuous behavior is observed, and cannot be explained within the scope of the respective situation by school staff (e.g. no trigger becomes apparent, teacher remains uncertain of consequences of an observed behavior), the respective school staff member is encouraged to report an observation to a central crisis prevention appointee (CPA) for a more in-depth assessment, e.g. of the student's general situation.

(2) A CPA is nominated by every school after the training. He/she merges information about a student, and decides if more extensive case management is required. The CPA's key responsibility is to collect further information about the student's situation from other sources (parents, other members of school staff, official documents) and putting all information together in order to conduct a more informed 
assessment of the conspicuous behavior. If the CPA is unsure whether an observation indicates a personal student crisis or not, he/she reports his observations to a crisis prevention team (CPT) for a further, teambased review.

(3) The CPT conducts a collaborative, evidencebased threat assessment, and develops an intervention plan to provide student support. A school's CPT was either previously established in order to follow the guidelines of emergency response plans in Germany, or is formed as a consequence of the NETWASS training, and besides the CPA should involve the school principal, specially trained members of the school staff, the school's social worker, and the homeroom teacher of the student concerned. In a case management session they discuss all available information with the key question in mind: Is the student experiencing a psychosocial crisis that puts him or her at risk for planning and conducting a violent act? In a step-by-step procedure following a structured case management protocol, the CPT evaluates whether the student shows symptoms of a psychosocial crisis or serious warning behavior for targeted violence, and whether the student's overall situation reflects individual vulnerabilities and social strain factors, but also individual resources and protective factors. After this, the CPT elaborates an intervention plan with appropriate interventions helping the student to cope with the crisis and end a threatening situation, by minimizing strains, and maximizing protective factors.

It follows (4) case monitoring in order to evaluate the effectiveness of the case management plan. Staff members responsible for case monitoring should give feedback to the CPT whether measures have started, were rejected, canceled, or ended, or whether other important events have occurred that require a new assessment by the team.

In every step, the specific emergency response plans have to be considered and followed, if a case requires immediate action.

\section{Results on Effectiveness and Program Acceptance}

For an accompanying evaluation study to examine program impact, processes, and everyday usefulness, the NETWASS program has been implemented in 108 schools in three of the 16 German Federal States (Leuschner et al., 2017).

\section{Sample and recruitment process}

The recruitment process for the evaluation study obtained a sample of 108 schools with 5,610 teachers and over 80,000 students. Participants were recruited in a stratified cluster sample from three German Federal States: (1) Berlin, as the German capital representing an urban setting with a large low-income and ethnically diverse population; (2) Brandenburg being a sparsely populated, rural state with a low- to middle-income, ethnically homogeneous population; and (3) Baden-Wurttemberg, a densely populated, rural/suburban state with a middle- to high-income population. After a 7-month-period of project implementation, the program had been implemented in 98 schools in Germany $(90 \%$ of trained schools; 10 schools enclosed in a pilot study were excluded for the following analyses). Evaluation data from 3,473 school staff participants (teacher, social worker, and administration staff) were collected in a quasi-experimental comparison group-design at three measurement points (pre, post, 7-months-follow-up). The sample consisted of 27 primary schools, $25 \mathrm{sec}-$ ondary schools, 28 schools of higher academic track, and 18 vocational schools. On the individual level, $66.8 \%$ of school staff in the sample were women and the mean age was 46.2 years $(S D=10.7)$.

\section{NETWASS training}

Schools were provided with trainings via different implementation strategies, all following two steps: first, all school staff received a two-hour training enhancing their sensitivity for psychosocial crises in students. Second, crisis prevention teams were prepared and deployed at schools for the concrete threat assessment and an effective case management. The intense two-day training for the crisis teams focussed on practical application and included exercises on the basis of case examples. In the "extensive condition", the CPT was trained by psychologists of the NETWASS-team, as opposed to police officers and school psychologists in the "multiplier condition". The third, "self-instruction condition" consisted of a two-hour briefing that introduced an information brochure to the school staff and to the CPT. The CPT received no intense two-day training (for a detailed description of implementation conditions see Leuschner et al., 2017).

Trainings were based on a standardized program manual followed by every trainer. Schools within a training group were provided with equal material, 
learning methods, and dosage. Trainers were either psychologists from the research staff, school psychologists, or police officers. All trainers received standardized multiplier training and a trainer manual.

\section{Results on program acceptance}

Training satisfaction as measured by a 13-item training evaluation instrument including items on training didactic, schedule, subjective knowledge growth, and trainer skills (Cronbach's alpha $=.95$ ) was generally high $(M=3.80 ; \mathrm{SD}=.80,5$-point scale). Overall program acceptance was measured after seven months based on CPT members' approval to statements on program implementation. Ratings indicated the appropriateness of the NETWASS program for structured threat assessment $(92.8 \%$ approval) with assessment criteria being helpful to also identify students in crisis (88.9\% approval), and the recommended team structure as suitable for case management (90.3\% approval). Additionally, items on the danger of student stigmatization, and additional work load were disapproved: Only 6.3\% claimed student stigmatization by the program, and increased workload was moaned by $26.4 \%$.

\section{Results on effectiveness}

Using a quasi-experimental, comparison group design with three measurement points and a longterm follow-up with schools randomly allocated to implementation conditions, we investigated effectiveness of the NETWASS program in German schools under every-day conditions. Results revealed increased school staff expertise on the topic of school shootings and improved skills and confidence to evaluate threats and adolescent crises. As measured by case vignettes, school staff's abilities to identify students experiencing a crisis improved, and schools were more able to provide help and support (for a detailed report of differential effects of implementation conditions see Leuschner et al., 2017).

Additionally, positive secondary effects related to school climate including improved confidence in a school's organizational structure, improved teacherstudent interaction, and pronounced school staff cohesion and feelings of safety were reported. The positive changes emerged with equal or even effect sizes higher than those found in evaluation studies of preventive interventions primarily designed for e.g. improvements in school climate (Thapa et al., 2012). Moreover, in qualitative follow-up interviews, school staff members reported positive experiences with external partners during the sevenmonth-implementation period (e.g. in the context of case work), which then resulted in a greater trust in external partners as measured by the follow-up questionnaires.

\section{Results on case identification and management}

The implementation of the NETWASS program resulted in the identification of students showing crisis symptoms, or warning behavior for targeted violence. Seventyfive schools reported cases showing warning behavior or crisis symptoms, and a total of 228 case management sessions was conducted (2.5 per school). Reported cases were categorized into high (ca. 8\%) and low risk cases (Sommer et al., 2016). This percentage is similar to the percentage that Cornell and Sheras (2006) identified as very serious, substantive threats.

In terms of early crisis prevention, trained school staff members were able to identify symptoms and vulnerabilities not necessarily connected to the threat of violence. This indicated that the interventions initiated by the schools may have helped troubled students before their thoughts and feelings turned into violent fantasies and planning behavior. Preliminary results from the analysis of case management protocols reveal a correspondence of the number of measures implemented with the number of risk factors identified in a case, as well as with the level of risk. Furthermore, CPT self-reports indicate a high adherence to the structured protocol for case management. Apparently, the NETWASS preventive model was used according to manual recommendations and instructions for case work by the schools.

To summarize, with only a moderate degree of staff training required to implement the program, teachers' expertise and evaluation skills to identify and deal with students experiencing a psychosocial crisis significantly improved. Results emphasize an overall fit between schools' needs and program components, and the NETWASS training approach was accepted by the majority of trained teachers in Germany.

\section{A Crisis Prevention Program for Schools to Prevent Pathways Into (Violent) Extremism?}

Recent acts of terrorism in Europe were perpetrated by so called 'homegrown' people, rather than by foreign - for example Islamist - groups. Consequently, a 
process of violent radicalization, extremism respectively was proposed to explain how these ordinary people were recruited and persuaded to give their lives (Bhui, Hicks, Lashley, \& Jones, 2012; Klausen et al., 2016). The term "radicalization" "has come to be used to define the process through which an individual or a group considers violence as a legitimate and a desirable means of action" (Davies, 2009, p. 12) although other scholars prefer to use the term "violent extremism" as radicalisation is - in most cases - not associated with violent behaviour. With the development of several radicalization process models, there is a difficulty involved in describing a single pathway into radicalization, or creating profiles of radicals as a common starting point in the debate on effective safety policies. Since surveillance and control measures have obvious limitations, cause huge costs and can potentially undermine privacy, prevention efforts must be increased (Madriaza \& Ponsot, 2015). However, according to a systematic review of the International Centre for the Prevention of Crime (ICPC), most authors agree that empirical evidence for radicalization prevention is insufficient (NasserEddine et al., 2011; Zeiger \& Aly, 2015; cf. Madriaza \& Ponsot, 2015).

A systematic review of interventions for the prevention of religious radicalization and violent extremism by Christmann (2012) found that the evidence base for effectively preventing violent extremism interventions is very limited and only few studies contained empirical data or systematic data analysis. However, more recently, promising studies have been published, for example Feddes, Mann, and Doosje (2015) found a training aiming at empowering individuals in combination with strengthening empathy and measures to affect attitudes toward ideology-based violence and own violent intentions and empathy to be a possibly effective preventive intervention to prevent violent radicalization. Although general approaches of prevention and educational approaches (e.g. Aly, Taylor, \& Karnovsky, 2014; Reeves \& Sheriyar, 2015; UNESCO, 2016) have already been propagated or even realized, a selective prevention approach through formal educational institutions at the primary, secondary, and higher education levels (cf. Rosen, 2010; Veenkamp \& Zeigler, n.d.) should be preferred.

Although there is no single profile or pathway for violent radicalization (Böckler, Leuschner, Roth, Zick, \& Scheithauer, 2018a; Böckler, Leuschner, Zick, \& Scheithauer, 2018b), or even speed at which it happens, there are general socio-economic, psycho- logical, and institutional factors that lead to violent extremism (Davies, 2008, p. 12): "Push Factors drive individuals to violent extremism, such as: marginalization, inequality, discrimination (... ). Pull Factors nurture the appeal of violent extremism, for example: the existence of well-organized violent extremist groups with compelling discourses (...). Finally, there are contextual factors that provide a favourable terrain to the emergence of violent extremist groups". Following a public health approach Bhui et al. (2012) summarized individual risk and protective factors for violent radicalization (p. 3; cf. Klausen et al., 2016):

- "Risk factors: Young people facing transitions: education, place, family, religion and so on; cognitive and social openings to new influences; social isolation and exclusion; grievances about discrimination that may be personal, related to unfair treatment at work, access to health care or about other inequalities in society; unemployment; migrant status and experiences before and after immigration; international conflict that is considered unjust against a group with which individual identifies on religious, national or cultural grounds; perceived threat to family and cultural group; marginalized and traditional cultural identities; discrimination thought to explain group inequalities in health and social status and access to wealth; not able to negotiate needs and protest through non-violent and democratic means; contact with influential or charismatic leaders who justify terrorism (for example, in prisons, or in schools or universities).

- Protective factors: Social support; social cohesion; social capital and trust in institutions; feeling of safety and security in neighborhood; integrated cultural identity; employment success; access to democratic means for negotiating needs and opinions; access to critical religious leadership that can moderate and inform on legitimate religious perspectives." (cf. Lösel, King, Bender, \& Jugl, 2018).

Cole, Alison, Cole, and Alison (2009) summarize the following risk factors for violent extremism (p. 7): "Cultural and/or religious isolation, isolation from family, risk taking behaviours, sudden change in religious practice, exposure to violent rhetoric, negative peer influences, isolated peer group, hate rhetoric, political activism, basic paramilitary training, travel/residence abroad". Additionally, Cole et al. (2009, p. 13) summarize "red flag" risk factors as 
indicators for individuals being already on the way to becoming involved in violent extremism: "death rhetoric, being a member of an extremist group, contact with known recruiters/extremists, advanced paramilitary training, overseas combat". To sum it up: research on (violent) radicalization in adolescents shows many overlaps with research on developmental pathways towards school shootings - including certain risk factors, and even warning behaviors.

Several researchers (Böckler et al., 2018a, b; McCauley \& Moskalenko, 2008; McCauley, Moskalenko, \& Van Son, 2013; Zierhoffer, 2014) argue that violently radicalized lone-wolf terrorists may have characteristics in common with other types of severe targeted violence, such as school shooters. McCauley et al. for example found four characteristics common for both school attackers and assassins: perceived grievance, depression, a personal crisis, and history of weapons use outside the military. Radicalization of adolescents and young adults leading to violent extremism is a process including observable behaviour changes, changes in attitudes, beliefs, and norms of affected individuals. It is therefore important to consider preventing violent extremism and radicalization within a broader context of social and personal development (Cole et al., 2009).

Thus, according to these result, school shootings can be considered as one type of violent extremism with similarities with other types of violence such as Islamist violent extremism or political violent extremism, including an observable process of radicalization. For example, Klausen et al. (2016, p. 69) summarize current findings from radicalization research which align with findings from studies on cases of severe targeted violence at schools:

1. "Radicalization follows a predictable sequential pathway exhibited in behavioral changes.

2. Increased commitment is indicated by simultaneously occurring changes in behavior that precede violent action.

3. The radicalizing individual will engage in public activity before moving on to the final cataclysmic action.

4. The process of radicalizing to the point of carrying out violent action is measured in months and years rather than days and weeks."

Similarly, UNESCO (2016) has described behaviours that can be signs of radicalization, such as sudden break with the family and long-standing friendships, sudden drop-out of school and conflicts with the school, changes in attitudes and behaviour towards others (e.g. antisocial comments, rejection of authority, refusal to interact socially, signs of withdrawal and isolation), or regular viewing of internet sites and participation in social media networks that condone radical or extremist views.

Preventive interventions have to address individuals within the "process towards violent extremism", vulnerable individuals respectively - and for this different domains have to be considered such as the school environment, the family environment, the police etc. "At the moment, it is difficult to target preventive interventions at individuals who plot terrorist attacks because they are not particularly identifiable by demographic or personal characteristics, or by psychopathology, and there is often no formal membership structure or hierarchy among violent radicalized groups. However, evidence suggests that a useful focus is on young people who are vulnerable to radicalizing influences because of isolation or marginalization, particularly as they are likely to be accessible to interventions while in full time education during adolescence and young adulthood when identity-related psychological and social transitions are common" (Bhui et al., 2012, p. 6).

As vulnerability is not static and not a "castiron" prediction of future behaviour (Cole et al., 2009) it is necessary to establish professional networks and easy-to-access counselling interventions, to establish a network of trained professionals from different environments (e.g. teachers, police officers, social workers, threat assessment experts), to develop preventive interventions including anti- and deradicalisation strategies for a successful prevention of violent extremism, and to develop easy-to-access and easy-to-handle training and communication structures. It will be important to implement programs that train parents and increase public awareness, distributed widely within civil society and the government, and work to make individuals aware of the radicalization of children. This will be applicable to community spaces such as schools, religious areas, and the training of youth themselves.

\section{Concluding Remarks}

The NETWASS evaluation study was the first large-scale evaluation study of a threat assessment program in Europe using a teacher education/training approach. Results clearly indicate practical feasibility and effectiveness in identifying students on a nega- 
tive developmental pathway. This has been proven for even early stages of negative development, and long before violent thoughts turn into fantasies and planning behavior.

In the present article, school shootings were contextualized as a potential endpoint of a negative development during adolescence. Despite the specific dynamics associated with radicalization, similarities of pathways into severe targeted school violence, and radicalization, respectively, became visible (cf. Böckler et al., 2018a, b), allowing to a certain degree for transferability of the NETWASS model to the prevention of (violent) radicalization: Research findings on the long-term development of radicalized attitudes call for a developmental perspective on crisis prevention as promoted in the NETWASS program manual. As we know so far, these pathways apparently have their beginning in adolescence, which requires a preventive approach using the school context as a setting for prevention. Furthermore, pathways into radicalization are accompanied by observable behavioral changes, similar to leakage and other warning behavior prior to a school shooting: Thus, a preventive approach that incorporates a training measure focusing on sensitization, and enabling school staff to identify warning signs seems a crucial foundation.

A modified version of the NETWASS trainings based on latest results from case study on radicalization would be a more specific tool to provide schools with knowledge necessary to prevent radicalization, while continuing to train and practice global skills of informed decision-making, fact-based threat assessment, protocol-guided case management, and building structures for information exchange in schools, as well as in cooperation with expert institutions dealing with (violent) radicalization and terrorism. By supporting the implementation of the NETWASS program into standard educational practice, school administrators, and policy makers can contribute to a healthy development of students and increase feelings of safety in students, parents, and school staff, considering additionally several important ethical issues (e.g. Baker-Beall, HeathKelly, \& Jarvis, 2015; Coppock, 2014; Coppock \& McGovern, 2014).

\section{Author Note and Acknowledgements}

The projects NETWASS (13N10689) and TARGET (13N12646) were funded by the Federal Ministry of Education and Research (BMBF), Germany. We thank our cooperating partners and participating schools. The senior author, Herbert Scheithauer, is member of the EU funded projects "Preventing Radicalisation Online through the Proliferation of Harmonised Toolkits" (PROPHETS) (this project has received funding from the European Union's Horizon 2020 research and innovation programme under grant agreement No 786894) and "Mapping, IdentifyiNg and Developing skills and opportunities in operating environments to cocreate innovative, ethical and effective ACTions to tackle radicalization leading to violent extremism" (MINDb4ACT) (this project has received funding from the European Union's Horizon 2020 research and innovation programme under grant agreement No 740543).

\section{References}

Aly, A., Taylor, E., \& Karnovsky, S. (2014). Moral disengagement and building resilience to violent Extremism: An education intervention. Studies in Conflict and Terrorism, 37, 369-385. doi: 10.1080/1057610x.2014.879379

Apelt, C. (2013). Ein systematisches Review zu nationalen und internationalen Bedrohungsanalyseansätzen (Threat Assessments) sowie Krisenpräventions- und Interventionsansätzen bei schwerer, zielgerichteter Gewalt an Schulen und Universitäten. [A systematic review of national and international threat assessment approaches as well as crisis prevention and intervention approaches to severe, targeted violence in schools and universities] Unpublished Master Thesis, Unit "Developmental Science and Applied Developmental Psychology", Freie Universität Berlin.

Baker-Beall, C., Heath-Kelly, C., \& Jarvis, L. (Eds.) (2015). Counter-radicalisation. Critical perspectives. London/New York: Routledge.

Bhui, K.S., Hicks, M.H., Lashley, M., \& Jones, E. (2012). A public health approach to understanding and preventing violent radicalization. BMC Medicine, 10. doi: 10.1186/1741-7015-10-16

Böckler, N., Leuschner, V., Roth, V., Zick, A., \& Scheithauer, H. (2018a). Blurred boundaries of lone-actor targeted violence: Similarities in the genesis and performance of terrorist attacks and school shootings. Violence and Gender, 5, 70-80. doi: 10.1089/vio.2018.0002

Böckler, N., Leuschner, V., Zick, A., \& Scheithauer, H. (2018b). Same but different? Developmental pathways to demonstrative targeted attacks-Qualitative case analyses of adolescent and young adult perpetrators of targeted school attacks and jihadi terrorist attacks in Germany. International Journal of Developmental Science, 12, 5-24. doi: 10.3233/DEV-180255

Böckler, N., \& Seeger, T. (2010). Schulamokläufer: Eine Analyse medialer Täter-Eigendarstellungen und deren Aneignung durch jugendliche Rezipienten. [School shooters: An analysis of medial representations of perpetrators and their appropriation by young recipients] Weinheim: Juventa-Verl.

Böckler, N., \& Seeger, T. (2013). Revolution of the dispossessed: School shooters and their devotees on the Web. In N. Böckler, 
T. Seeger, P. Sitzer \& W. Heitmeyer (Eds.), School shootings: International research, case studies and concepts for prevention (pp. 309-339). New York: Springer.

Böttger, A. (1998). Gewalt und Biographie. Eine qualitative Analyse rekonstruierter Lebensgeschichten von 100 Jugendlichen. [Violence and biography. A qualitative analysis of reconstructed life stories of 100 adolescents] Baden Baden: Nomos Verlagsgesellschaft.

Bondü, R., Cornell, D.G., \& Scheithauer, H. (2011). Student homicidal violence in schools: An international problem. New Directions for Youth Development, 129, 13-30. doi: 10.1002/yd.384

Bondü, R., \& Scheithauer, H. (2012). Media consumption in German school shooters. In G.W. Muschert \& J. Sumiala (Eds.), School shootings: Mediatized violence in a global age (pp. 69-89). Bingley: Emerald.

Bondü, R., \& Scheithauer, H. (2014a). Leaking and death-threats by students: A study in German schools. School Psychology International, 35, 592-608. doi: 10.1177/0143034314552346

Bondü, R., \& Scheithauer, H. (2014b). Narcissistic symptoms in German School shooters. International Journal of Offender Therapy and Comparative Criminology, 59, 1520-1535. doi: 10.1177/0306624x14544155

Bondü, R., \& Scheithauer, H. (2014c). Peer and teacher relationships in German school shooters. International Journal of Developmental Science, 8, 57-63. doi: 10.3233/DEV-140131

Bondü, R., \& Scheithauer, H. (2015). Kill one or kill them all? Differences between single and multiple victim school attacks. European Journal of Criminology, 12, 277-299. doi: 10.1177/1477370814525904

Christmann, K. (2012). Preventing religious radicalisation and violent extremism: A systematic review of the research evidence. Research report. Youth Justice Board. Retrieved from: http://eprints.hud.ac.uk/16198/.

Cole, J., Alison, E., Cole, B., \& Alison, L. (2009). Guidance for identifying people vulnerable to recruitment into violent extremism. University of Liverpool, School of Psychology. Retrieved from: http://safecampuscommunities.ac.uk/ uploads/files/2013/05/ivp_guidance_draft_v0.3_web_ version.pdf

Coppock, V. (2014). "Can you spot a terrorist in your classroom?" Problematising the recruitment of schools to the "war on terror" in the United Kingdom. Global Studies of Childhood, 4, 115125. doi: 10.2304/gsch.2014.4.2.115

Coppock, V., \& McGovern, M. (2014). "Dangerous minds"? Deconstructing counter-terrorism discourse, radicalisation and the "psychological vulnerability" of Muslim children and young people in Britain. Children \& Society, 28, 242-256. doi: 10.1111/chso. 12060

Cornell, D.G., \& Sheras, P.L. (2006). Guidelines for responding to student threats of violence. Boston: Sopris West Educational Services.

Cornell, D., Allen, K., \& Fan, X. (2012). A randomized controlled study of the Virginia Student Threat Assessment Guidelines in grades K-12. School Psychology Review, 41, 100-115.

Daniels, J.A., Bradley, M.C., Hays, M. (2007). The impact of school violence on school personnel: Implications for psychologists. Professional Psychology: Research and Practice, 38, 652-659. doi: 10.1037/0735-7028.38.6.652

Davies, L. (2009). Educating against Extremism: Towards a critical Politicisation of young people. International Review of Education, 55, 183-203. doi: 10.1007/s11159-008-9126-8
Feddes, A.R., Mann, L., \& Doosje, B. (2015). Increasing selfesteem and empathy to prevent violent radicalization: A longitudinal quantitative evaluation of a resilience training focused on adolescents with a dual identity. Journal of Applied Social Psychology, 45, 400-411. doi: 10.1111/jasp.12307

Fein, R. A., Vossekuil, B., Pollack, W. S., Borum, R., Modzeleski, W., \& Reddy, M. (2002). Threat assessment in schools. A guide to managing threatening situations and to creating safe school climates. Washington D. C.: United States Secret Service and United States Department of Education.

Filipp, H.S. (1997). Kritische Lebensereignisse.[Critical life events] München: Urban and Schwarzenberg.

Harding, D.J., Fox, C., \& Mehta, J.D. (2002). Studying rare events through qualitative case studies: Lessons from a study of rampage school shootings. Sociological Methods \& Research, 31, 174-217. doi: 10.1177/0049124102031002003

Hoffmann, J., Roshdi, K., \& Robertz, F. (2009). Zielgerichtete schwere Gewalt und Amok an Schulen. Eine empirische Studie zur Prävention schwerer Gewalttaten. [Targeted severe violence and amok in schools. An Empirical Study on the Prevention of Serious Violence] Kriminalistik, 63, 196-204.

Fox, C., \& Harding, D.J. (2005). School shootings as organizational deviance. Sociology of Education, 78, 69-97. doi: 10.1177/003804070507800104

Jüttner, J. (2006). German School shooting: Armed to the teeth and crying for help - SPIEGEL ONLINE - international. Retrieved from: http://www.spiegel.de/international/ german-school-shooting-armed-to-the-teeth-and-crying-forhelp-a-449814.html (Accessed: 30 January 2017).

Kidd, S.T., \& Meyer, C.L. (2002). Similarities of school shootings in rural and small town communities. Journal of Rural Community Psychology, E5 (1).

Klausen, J., Campion, S., Needle, N., Nguyen, G., \& Libretti, R. (2016). Toward a behavioral model of "Homegrown" Radicalization Trajectories. Studies in Conflict \& Terrorism, 39, 67-83. doi: 10.1080/1057610x.2015.1099995

Langman, P. (2009). Rampage school shooters: A typology. Aggression and Violent Behavior, 14, 79-86. doi: 10.1016/j.avb.2008.10.003

Langman, P. (2014). Sebastian Bosse's journal. Translated from German by Birgit Laramie, M.A. Adjunct Lecturer in German, Moravian College, Lehigh University, and Lafayette College. Retrieved from: https:// schoolshooters.info/sites/default/files/bosse_journal_1.0.pdf (Accessed: 31 January 2017).

Leary, M.R., Kowalski, R.M., Smith, L., \& Phillips, S. (2003). Teasing, rejection, and violence: Case studies of the school shootings. Aggressive Behavior, 29, 202-214. doi: 10.1002/ab. 10061

Leuschner, V., Bondü, R., Schroer-Hippel, M., Panno, J., Neumetzler, K., Fisch... \& Scheithauer, H. (2011). Prevention of homicidal violence in schools in Germany: The Berlin Leaking Project and the networks against school shootings project (NETWASS). New Directions for Youth Development, 129, 61-78. doi: 10.1002/yd.387

Leuschner, V., Schroer-Hippel, M., Bondü, R., \& Scheithauer, H. (2013). Indicated prevention of severe targeted school violence: The Program Networks Against School Shootings (NETWASS). In N. Böckler, T. Seeger, W. Heitmeyer, \& P. Sitzer (Eds.), School shootings: International research, case studies and concepts of prevention (pp. 401-429). New York: Springer. 
Leuschner, V., Fiedler, N., Schultze, M., Ahlig, N., Göbel, K., Sommer, F.... \& Scheithauer, H. (2017). Prevention of targeted school violence by responding to students' psychosocial crises: The NETWASS program. Child Development, 88, 68-82. doi: $10.1111 /$ cdev. 12690

Levin, J., \& Madfis, E. (2009). Mass murder at school and cumulative strain: A sequential model. American Behavioral Scientist, 52, 1227-1245. doi: 10.1177/ 0002764209332543

Lösel, F., King, S., Bender, D., \& Jugl, I. (2018). Protective factors against extremism and violent radicalization: A systematic review of research. International Journal of Developmental Science, 12, 89-102. doi: 10.3233/DEV-170241

Madriaza, P., \& Ponsot, A.S. (2015). Preventing radicalization: A systematic review. Technical Report from the International Centre for the Prevention of Crime (ICPC). doi: 10.13140/RG.2.1.4862.1682

McCauley, C., \& Moskalenko, S. (2008). Mechanisms of political radicalization: Pathways toward terrorism. Terrorism and Political Violence, 20, 415-433. doi: 10.1080/09546550802073367

McCauley, C., Moskalenko, S., \& Van Son, B. (2013). Characteristics of lone-wolf violent offenders: A comparison of assassins and school attackers. Perspectives on Terrorism, 7 (1) [Online Article]. Retrieved from http://www.terrorismanalysts.com/pt/index.php/pot/article/ view/240/html.

McGee, J. P., \& DeBernardo, C. R. (1999). The classroom avenger. The Forensic Examiner, 8, 1-16.

Meloy, J.R., Hoffmann, J., Guldimann, A., \& James, D. (2012). The role of warning behaviors in threat assessment: An exploration and suggested typology. Behavioral Sciences \& the Law, 30, 256-279. doi: 10.1002/bsl.999

Meloy, J.R., \& O'Toole, M.E. (2011). The concept of leakage in threat assessment. Behavioral Sciences \& the Law, 29, 513527. doi: $10.1002 / \mathrm{bs} 1.986$

Nasser-Eddine, M., Garnham, B., Agostino, K., \& Caluya, G. (2011). Countering violent extremism (CVE). Literature review. Edinburgh South Australia. Retrieved from http://dspace.dsto.defence.gov.au/dspace/handle/1947/10150.

Newman, K., Fox, C., Harding, D.J., Mehta, J., \& Roth, W. (2004). Rampage. The social roots of school shootings. New York: Perseus Books.

O'Toole, M.E. (1999). The school shooter: A threat assessment perspective. Quantico, VA: National Center for the Analysis of Violent Crime, Federal Bureau of Investigation.

Payne, A.A., Gottfredson, D.C., \& Gottfredson, G.D. (2006). School predictors of the intensity of implementation of schoolbased prevention programs: Results from a national study. Prevention Science, 7, 225-237. doi: 10.1007/s11121-0060029-2

Reeves, J., \& Sheriyar, A. (2015). Addressing radicalisation into the classroom - A new approach to teacher and pupil learning. Journal of Education and Training, 2, 20-39. doi: 10.5296/jet.v2i2.7129

Robertz, F. (2004). School Shootings. Über die Relevanz der Phantasie für die Begehung von Mehrfachtötungen durch Jugendliche. [School Shootings. On the relevance offantasy for the commission of multiple killings by adolescents] Frankfurt: Verlag für Polizeiwissenschaft.

Rosen, S.D. (2010). Pathways to prevention? Evaluating the United Kingdom's approach to counter-radicalization. Thesis submitted to the Faculty of the Graduate
School of Arts and Sciences of Georgetown University, Washington D.C. Retrieved from: https:// repository.library.georgetown.edu/handle/10822/553573

Ryan-Arredondo, K., Renouf, K., Egyad, C., Doxey, M., Dobbins, M., Sanchez, S., \& Rakowitz, B. (2001). Threats of violence in schools: The Dallas independent school district's response. Psychology in the Schools, 38, 185-196. doi: 10.1002/pits.1009

Scheithauer, H., Leuschner, V., \& NETWASS Research Group (2015). Krisenprävention in der Schule. Das NETWASSProgramm zur frühen Prävention schwerer Schulgewalt. [Crisis prevention in schools. The NETWASS program for early prevention of servere school violence] Stuttgart: Kohlhammer.

Sommer, F., Fiedler, N., Leuschner, V., \& Scheithauer, H. (2016). Strukturen zur Identifikation und Bewertung krisenhafter Entwicklungen im Kindes- und Jugendalter - Das NETWASSKrisenpräventionsverfahren für Schulen. [The NETWASS prevention model for early identification and assessment of adolescents in psychosocial crisis] Zeitschrift für Kinder- und Jugendpsychiatrie und Psychotherapie, 44, 198-207. doi: I 10.1024/1422-4917/a0004

Sommer, F., Leuschner, V., \& Scheithauer, H. (2014). Bullying, romantic rejection, and conflicts with teachers: The crucial role of social dynamics in the development of school shootings A systematic review. International Journal of Developmental Science, 8, 3-24. doi: 10.3233/DEV-140129

Syvertsen, A.K., Flanagan, C.A., \& Stout, M.D. (2009). Code of silence: Students' perceptions of school climate and willingness to intervene in a peer's dangerous plan. Journal of Educational Psychology, 101, 219-232. doi: 10.1037/a0013246

Thapa, A., Cohen, J., Higgins-D'Alessandro, A., \& Guffey, S. (2012). School climate research summary (Issue Brief No. 3). New York: National School Climate Center. Retrieved from: www.schoolclimate.org/climate/research.php.

United Nations Educational, Scientific and Cultural Organization (UNESCO) (2016). A teacher's guide on the prevention of violent extremism. Paris: UNESCO.

Van Dreal, J. (2011). Assessing student's threats. A handbook of implementing the Salem-Keizer System. Maryland: Lanham.

Veenkamp, I., \& Zeiger, S. (n.d.). Countering violent extremism: Program and policy approaches to youth through education, families and communities. Retrieved from http://inee-assets.s3.amazonaws.com/ resources/D._INEE_Round_Table_Background_Reading _FINAL_Veenkamp_Zeiger_Youth_CVE_NATO_ARW.pdf.

Verlinden, S., Hersen, M., \& Thomas, J. (2000). Risk factors in school shootings. Clinical Psychology Review, 20, 3-56. doi: 10.1016/s0272-7358(99)00055-0

Vossekuil, B., Fein, R. A., Reddy, M., Borum, R., \& Modzeleski, W. (2002). The final report and findings of the Safe School Initiative: Implications for the prevention of school attacks in the United States. Washington DC: U.S. Secret Service National Threat Assessment Center, U.S. Department of Education, and National Institute of Justice.

Wieczorek, A. (2010). Schülerattentate an deutschen Schulen. Mythen, Fakten und Schlussfolgerungen für die polizeiliche Praxis. [Attacks by students at German schools. Myths, facts and conclusions for police practice] Kriminalistik, 64, 153160.

Zeiger, S., \& Aly, A. (2015). Countering violent extremism: Developing an evidence-base for policy and practice. Perth: Curtin University. 
Zierhoffer, D. (2014). Threat assessment: Do lone terrorists differ from other lone offenders? Journal of Strategic Security, 7, 48-62. doi: 10.5038/1944-0472.7.3.3

\section{Bio Sketches}

Nora Fiedler is a psychologist working as a research associate at Freie Universität Berlin, Unit "Developmental Science and Applied Developmental Psychology". Her research interests are violence research, crisis prevention in schools, and early threat assessment of violence.

Vincenz Leuschner is professor of Criminology and Sociology at the Berlin School of Economics and Law, Department Police and Security Management. From 2009 to 2016 he was research assistant at Freie Universität Berlin. His research interests are violence research, sociology of social problems, victimology, developmental criminology, crime prevention and security research.
Herbert Scheithauer is Professor for Developmental and Clinical Psychology at Freie Universität Berlin, Germany, and Head of the Unit "Developmental Science and Applied Developmental Psychology". His research interests are bullying, cyberbullying, and the development and evaluation of preventive interventions.

Friederike Sommer is a psychologist working as a research associate at the Berlin School of Economics and Law, Department Police and Security Management. She was part of the NETWASS research team, working from 2010 to 2017 at Freie Universität Berlin. Her research interests are violence research, criminology, social and emotional dynamics within developmental processes and clinical psychology. 